\title{
Correction to: Correlation between Wall Shear Stress and Acute Degradation of the Endothelial Glycocalyx during Cardiopulmonary Bypass
}

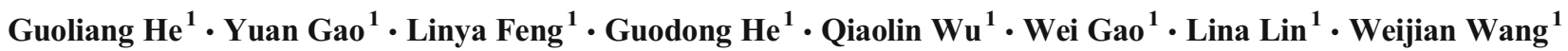

Published online: 12 July 2021

(C) Springer Science+Business Media, LLC, part of Springer Nature 2021

\section{Correction to: Journal of Cardiovascular Translational}

Research (2020) 13:1024-1032.

https://doi.org/10.1007/s12265-020-10027-2

This article was updated after its original publication to add Lina Lin as co-corresponding author (at: wzlinlina@163.com).

The original article has been updated.

Publisher's Note Springer Nature remains neutral with regard to jurisdictional claims in published maps and institutional affiliations.

The online version of the original article can be found at https://oi.org/ $10.1007 / \mathrm{s} 12265-020-10027-2$

\footnotetext{
Lina Lin

wzlinlina@163.com

$\triangle$ Weijian Wang

wangwj2002@hotmail.com

1 Department of Anesthesiology, The First Affiliated Hospital of Wenzhou Medical University, Wenzhou, Zhejiang 325000, China
} 